\title{
RESCATES
}

En este número rescatamos una carta que habla de los ámbitos secretos de Rafael Sánchez Ferlosio a principios de los años sesenta: su obstinada y casi obsesiva dedicación a la investigación lingüística. La carta es casi una prolongación de esos desvelos: la envió en 1965 a José María Castellet, a la sazón director de la editorial Península, rompiendo una lanza en favor de la publicación de Enseñar y aprender. El libro rondaba por la mesa de otros amigos, como Javier Pradera, editor entonces en Alianza, y lo firmaba el infatigable Víctor Sánchez de Zavala. Según se verá, el enfoque y la prosa de Sánchez de Zavala habían recibido duras críticas entre los primeros lectores del mecanuscrito. Con un fino olfato que es ya proverbial, Castellet puso aquella carta vindicativa al frente de la edición del libro para que escoltara, junto con un prólogo de José Luis L. Aranguren, los primeros pasos de una obra que ambicionaba, como tantas en su tiempo, reformar los usos intelectuales del país.

\section{CARTA-ENVÍO ${ }^{1}$}

Querido Castellet:

Posiblemente no te entendí por teléfono, pues te estuve esperando en casa aquella misma mañana; después he conjeturado que si decías que mandabas a Juan como «embajador» debía de ser para que le expusiera a él lo que a ti quería haberte expuesto; pero no llegué a hacerlo porque se me voló el goytisolo antes de que en mi tarda mente pudiese cuajar tan obvia conjetura. De todas maneras, aún creo estar a tiempo de sacar la cuestión a relucir: se trata del libro que quiere publicar mi amigo Víctor Sánchez de Zavala, persona a la que conozco y vengo tratando desde hace unos dieciocho años, y en una relación no meramente familiar sino también intelectual, de suerte que son muchos los intereses y las curiosidades comunes; esto tengo que 
reconocerlo lealmente, por lo que pueda desautorizar mi gestión en su favor — pues no de otra cosa se trata-, ya que probablemente me ha de hacer difícil alcanzar la objetividad que desearía. Pero han venido aquí a concurrir además otros factores, que en la misma medida en que alejan todavía más esa objetividad de mis alcances hacen presión sobre mi ánimo para que no pueda dejar de escribir esta carta, pues han desencadenado en mí una simpatía —siempre, en principio, inoportuna en la vida intelectual — que me hace tomar el asunto «como cosa mía». Esos factores son los siguientes: la peculiar animadversión que el original ha suscitado en algunas de las personas que lo han leído y la íntima comprensión que desde mis más personales experiencias tengo por las grandes dificultades de estilo que constituyen la más declarada aunque me sospecho que no la más poderosa-motivación de la repulsa. Yo, que llevo ocho años peleando con mis cada día más voluminosos papeles, sin conseguir acercarme —antes, por el contrario, me temo que alejándome cada vez más- a un estilo expositivo mínimamente viable, no puedo por menos de considerar (cada uno cuenta de la feria según le va en ella) este problema como uno de los más serios que, en las circunstancias actuales, pueden plantearse en la vida intelectual, a lo menos en lo que a la cultura española se refiere, y respetar, por lo tanto, de todo corazón, cualesquiera esfuerzos — por insuficiente e hirsuto que llegue a ser su resultado- encaminados a romper con las arcaicas inercias verbales, en busca de un estilo cuya complejidad y sutileza estén a la altura de las difíciles cosas que es preciso decir; piensa en el disparatado y hasta ilegible estilo de Della Volpe; pues bien: la conciencia lingüística que su desafortunado intento supone es para mí mucho más valiosa y respetable, desde el punto de vista del porvenir de la cultura, que cualesquiera otras páginas de más agraciado aspecto y más agradecida lectura. No otra cosa es la que pienso del estilo de mi amigo, aunque no creo que llegue a ser tan extremoso como el del crítico italiano: en ambos casos — como en el mío propio- se trata fundamentalmente de lo que podría llamarse «construir la frase y el período en tres dimensiones», como ya la gramática oral nos permite construir sus partes; es decir, de no resignarse a poner — forzados por la linearidad del discurso común— en sucesión las relaciones en las que las exigencias del concepto piden una articulación lateral. Y el estilo buscado no se puede inventar sino ensayando y errando con libros que, aparte de llevar a los lectores a la conciencia de su necesidad y propagar entre ellos el acicate de su búsqueda, vayan venciendo los prejuicios e inercias de un oído anquilosado en los carriles de lo inmediatamente comprensible. 
Así, pues, las resistencias enfrentadas por los lectores de sentido común al estilo de Sánchez de Zavala no son sino la manifestación patente de esas mismas inercias y prejuicios que se trata de vencer y que hacen tanto más evidente la conveniencia de libros como el suyo, aparte de la mayor o menor fortuna con que el problema del estilo se resuelva en cada caso — cosa que, en éste, incluso el propio autor está lejos de pensar haber logrado como se requiere-. Pero hay más todavía - y con ello accedemos imperceptiblemente a las otras motivaciones que sospecho escondidas detrás de la repulsa que el libro ha suscitado en algunos lectores psicológicamente caracterizados—, y es el hecho de que el desaforado personalismo vigente — que, nacido tal vez de la torpe politización actual de la cultura, se proyecta pelo a pelo sobre la vida intelectualexija de los libros que vengan a ser como una suerte de tajante, fideística y definitiva declaración de dogmas personales; exigencia la más anticientífica que pueda imaginarse, por cuanto, lejos de proyectarse el interés hacia la cosa y su propia verdad, lo vuelve enteramente hacia «la verdad de la persona», como si el libro no tuviese otra función que la de hacer saber a qué atenerse con respecto a ella; por eso un libro no es un libro cuando no se presenta como una exposición de conclusiones y declaración de principios e irrita en la misma medida en que, lleno de respetuosas vacilaciones y meras proposiciones de vías de investigación, no se presta a satisfacer aquellas apetencias; en una palabra siempre que en vez de ser el fin de un discurso no quiera ser más que su comienzo. Así, al autor que no enuncia convicciones definitivas (sencillamente porque no las tiene; aunque se piense que lo que pasa es que las oculta, confundiendo su rectitud científica con una especie de prudencia personal) se le tiene por un ser escurridizo, que no da la cara, cuando en verdad es el que más desprendidamente arriesga.

Pero allí donde los libros se busquen desde un verdadero interés hacia las cosas y no desde el personalismo del "a ver por dónde respira el tipo este», que no tiene más fin que averiguar «si es de los míos», allí donde los libros se lean olvidándose de que alguien los escribe, donde tengan otra función que la de servir de criterio para salvar a su autor o echarlo a la gehenna, allí donde se recuerde que quieren decir algo no ya para que sea comparado con otras opiniones sino contrastado con las cosas mismas, allí no puede producir irritación, sino todo lo contrario, un libro que se limite a suscitar y a proponer, a invitar al lector a que extienda la mirada sobre todo el panorama de las cosas que habría que tener en cuenta para encarar debidamente el asunto que se trata. $Y$ a este respecto no puedo por menos de encarecer el libro 
de mi amigo como un oasis de auténtica actitud científica en el desierto del afásico personalismo nacional; y aquí es donde, por segunda vez —la primera lo era en mi íntima comprensión hacia las dificultades del estilo-, pierdo la objetividad y me veo arrastrado inevitablemente a una simpatía que en sí misma no puedo considerar sino dañina para la vida intelectual, a una actitud de defensa que bien querría que las circunstancias me permitiesen deponer; pero si el desierto levanta sus simunes y cierra sus arenas contra la implantación de los oasis, yo no puedo por menos de apretar entonces casi acríticamente mis palmeras contra las de mi amigo, a fin de aumentar así las escasas probabilidades de que medren los cultivos que creemos necesarios. Pero esto no era más que una metáfora, que me ha apartado, como suele pasar, de la verdad, pues no es cierto que yo defienda, dejando al margen sus defectos, el libro de mi amigo porque considere su actitud conveniente para el ambiente científico español; no existe en absoluto semejante cálculo: se trata sencillamente de que los motivos - y no ya razones-que me creo haber adivinado tras el rechazo de este libro por algunos originan en mí una indignación que no puede sino ir en detrimento de la imparcialidad de mi defensa y me incitan a hacer la conjetura meramente sintomática —y por lo tanto desprovista de un legítimo apoyo probatorio- de que toca el asunto justamente como ha de ser tocado; indicio totalmente insuficiente - e inaceptable en tanto que argumento, como todos los que siguen el modelo de «arcessor ergo sum»— pero, con todo, indicio al fin: irrita, en el ambiente de tensiones ideológicas que padecemos, que, en torno a la enseñanza, no se haga apología ni dogmatismo, ni se repita una vez más la cantilena de un humanismo idílico, sino que se vaya en busca de datos a la neurocirugía y a la ciencia del lenguaje; irrita porque es introducir una complicación y una delicadeza que pone en cuarentena todos los planes y medios de enseñanza de una sociedad que cree saber muy bien cómo tiene que adoctrinar a sus vasallos; irrita porque ya meramente como actitud científica pone en evidencia la sumarísima brutalidad que semejante sociedad proyecta y se promete seguir proyectando sobre sí misma y sus propios componentes; irrita porque aspira a averiguar más de la cuenta; porque es científica, en una palabra. Esta censura a priori que ni siquiera espera a ver salir el libro para rebatirlo sino que se empecina en sofocarlo antes de su publicación, es lo que produce en mí esa reacción de simpatía que desearía poderte contagiar.

Mirando el libro desde dentro, yo no dispongo ni con mucho de los conocimientos necesarios para poder enjuiciar debidamente una obra fundamentada en copiosas y sistemáticas 
lecturas, las cuales hacen, por lo demás, que incluso los posibles errores se hallen a la altura de los tiempos, de manera que puedan, reconocidos como tales, resultar fecundos. De todos modos, estoy en gran parte de acuerdo no sólo con su línea científica sino con sus observaciones singulares, en la medida en que se me alcanzan, e inclusive con sus propuestas puramente pragmáticas — que, por lo demás, ocupan una parte muy secundaria del contexto-, como la invitación a la eliminación de los profesores tal y como hasta la fecha se conciben, pues obviamente su origen se remonta a los antiguos «lectores» — todavía en italiano la clase se llama lezione- de cuando el carácter manuscrito de los libros hacía imposible su proliferación, y que por la inercia y los intereses creados, después de que la imprenta los hubo hecho totalmente innecesarios, encontraron toda suerte de razones ad hoc para justificar su pervivencia. Pero posiblemente no hay nada tan fecundamente promotor de la subjetividad intelectual como el esfuerzo de desentrañar y hacer revivir un texto escrito, sin la ayuda de nadie; esfuerzo en el que somos agentes y no meros pacientes de nuestro aprendizaje.

También, sin embargo, hay cosas con las que no estoy de acuerdo, como con la beligerancia — por lo demás tampoco demasiado grande_ que se da en el libro a la definición del lenguaje como «un medio de comunicación», que es una verdad de monsieur de la Palisse, esto es, una perífrasis o una tautología — aunque no quiero tampoco afirmar que toda perífrasis sea siempre totalmente improductiva en el razonamiento-, pues siempre que se trata de realizar esta significación, es decir, de ver lo característico de esa clase de cosas que se llaman «medios de comunicación», nos vemos inevitablemente remitidos a la experiencia del propio lenguaje, que se constituye en el arquetipo fundamental de ellas; o sea que la definición «el lenguaje es un medio de comunicación» tenía que haber sido precedida, antes de ser tomada en consideración y para restringir aun más la escasa beligerancia que se le concede, de una crítica interna que nos hiciese ver en qué medida viene a ser equivalente a decir «el lenguaje es de la clase de cosas que de algún modo son como el lenguaje», ya que el lenguaje mismo es la experiencia matriz que ha permitido configurar esa clase de cosas que llamamos «medios de comunicación».

En fin, no canso más; un encarecimiento y un saludo de

Ferlosio 